\title{
The Driving Forces behind the Victory of Donald J. Trump
}

\author{
An Empirical Analysis of the 2016 U.S. Presidential Election
}

\section{Carla Schmitt ${ }^{1}$}

\begin{abstract}
The purpose of this study is to establish how important economic factors are for individual voting behaviour. To that regard the analysis focuses on determining which factors influenced the outcome of the 2016 U.S. presidential election by considering county level data on several economic and non-economic variables. Individual voting behaviour is thus inferred from county level variation. The results of the analysis suggest that economic factors, especially income and income inequality, have a considerable impact on electoral choice. Further, several noneconomic factors are predicted to influence the electoral outcome as well. The magnitude of the effect economic and non-economic variables exhibit is comparable, stressing that economic factors were important determinants of the outcome of the 2016 U.S. presidential election and significantly influence voting behaviour.
\end{abstract}

\section{Introduction}

The United States (U.S.) president is generally seen as one of the most powerful world leaders, which is why the $58^{\text {th }}$ U.S. presidential election in 2016 was watched with interest by many people around the world. Although up to the day of the election, predictions and public opinion polls saw Hillary Clinton, the Democratic Party candidate, as the clear leader in the race for the office (Andrews, Katz, \& Patel, 2016), the Republican Party candidate, Donald Trump, made the race and was elected the $45^{\text {th }}$ president of the United States of America on 8 November 2016 (BBC, 2016). Trump's victory against the incumbent party's candidate has since been heatedly discussed in the media. Based on Edision Research statistics many discussions of the outcome focused on characteristics like age group, race or education (BBC, 2016). The economist Branko Milanovic however, links the election's result to his theory about global income inequality, reasoning that stagnating growth in the U.S. middle class due to globalization and its trends has lead large parts of the population to vote for Donald Trump (Milanovic, 2016).

Economic and political literature strongly suggests that various economic factors influence voting behaviour and can successfully predict election outcomes. In a general literature review Lewis-Beck and Stegmaier (2000) find that economic conditions influence the electoral outcomes in democracies around the world. Kramer's (1971) early contributions examined the relationship between US congressional electoral outcomes and economic conditions. Indeed he discovered in his study that "election outcomes are in substantial part responsive to objective changes occurring under the incumbent party; they are not "irrational," or random, or solely the product of past loyalties and habits, or of campaign rhetoric and merchandising" (Kramer, 1971, p. 140). According to him, especially economic fluctuations influence

${ }^{1}$ Carla Schmitt received a bachelor degree in Economics and Business Economics at Maastricht University in 2017 and currently works for the Telekom Deutschland GmbH. Contact: info@carla-c-schmitt.de 
electoral outcomes. In an attempt to build a model that incorporates the most widely supported theories of voting behaviour, Fair (1978) establishes that changes in real economic activity in the election year had important effects on the behaviour of voters. Markus (1988) tested the impact of economic circumstance on electoral choice. More specifically, he reasons that voting behaviour could be motivated by individual as well as national economic circumstances.

This study addresses the question: How important are economic factors when it comes to voting behaviour? The main interest of the work therefore lies with the individual. For that purpose, the analysis focuses on the 2016 U.S. presidential elections and considers county-level data in order to infer individual (or group) voting behaviour. With regard to relevant research in the field, combining existing theories in a model in order to analyse the most recent U.S. presidential election can be understood as a valuable addition to the literature.

The purpose of this study thus is to analyse and answer the research question in light of the 2016 U.S. presidential election by examining which factors lead to Donald Trump's victory. To do so the paper will proceed in the following way. First, a short literature review is presented to build the theoretical framework this study is based on. Second, the method used for the analysis is explained and its results are presented. Third, the research findings are critically discussed and interpreted. Finally, the model's applicability to other elections is tested by applying it to the 2012 U.S. presidential election and an overall conclusion of the analysis and results is drawn.

\section{Towards a Theory of Voting Behaviour}

\subsection{Existing Research and Theories}

There are several relevant studies that have attempted to establish a relationship between a range of economic variables and electoral outcomes. The four studies presented below used different approaches to form widely recognized theories of voting behaviour and therefore build a solid theoretical framework for this study.

The first work by Kramer (1971) attempts to link congressional election outcomes to several economic factors. He specifically looked at the share of votes the Republican Party obtained in the Congressional Elections from 1896 to 1964, excluding the years 1912,1918, 1942 and 1944 (due to difficulties in applying the model in 1912 and the possible bias that could be caused by wartime conditions in the other years). The estimations of the model included four economic variables, namely monetary income, prices, real income and unemployment for the period analysed. Kramer's results were quite conclusive, stating that unemployment and inflation mostly have no significant impact on electoral outcome, whereas real personal income does.

Second, the economist Fair (1978) built a model to analyse the effect of economic events on US presidential elections, seeking to incorporate the most supported theories of voting behaviour at the time. This first study concentrated on the period from 1916 to 1976 (and has since been continuously updated for more recent elections). For the estimation of the model the annual data of three economic variables, namely the unemployment rate, real GNP per capita and the GNP deflator were considered. Fair's main result is that change in real economic activity in the year before the election has an

\footnotetext{
$16 \mid$\begin{tabular}{l|l} 
Marble \\
Research
\end{tabular} Papers
} 
important effect on the electoral outcome. This result holds for each of the three economic variables examined, although evidence is strongest for real GNP per capita.

Third, Markus (1988) leans on such research and attempts to explain individual voting behaviour, especially whether voters focus on their personal economic situation or the overall national economic situation when making an electoral choice. He uses the annual change in real disposable income per capita as a voter's indicator for national economic circumstances and data from a survey in order to observe perceived changes in voters' personal income in election periods. The study considers eight consecutive presidential elections in the years from 1956 to 1984 . Markus framed his work similar to Kramer's (1971) by analysing the support a voter gives to the incumbent based on the economic factors tested. The main findings of his work are that positive changes in national real disposable income increase the probability of a vote for the incumbent. Changes in personal income, as observed through the survey results on the contrary only moderately influenced voting behaviour in the period observed.

Lastly, Tufte (1975) analysed fluctuations in Midterm Congressional Elections for the period of 1938 to 1970. In his model he included the voter's evaluation of presidential performance as well as the economic condition one year prior to the elections. The economic condition is approximated by real disposable personal income per capita. Tufte's main results are that for the relevant period, the election outcomes are explained by presidential approval and economic conditions prior to the elections.

Besides empirical evidence for the relation between several economic variables and electoral outcomes, two main theories can generally be taken away from the existing literature on voting behaviour. The retrospective voter and the theory of the performance evaluating voter are general theories about the period or point in time the voter considers when evaluating economic circumstances.

Theory of the Retrospective Voter

Fiorina (1978) adapted a micro approach and concentrated on the individual voter rather than on the overall macroeconomic conditions. He concentrates on the theory of the retrospective economic voter, who observes the economic conditions prior to the elections in order to evaluate the incumbent's performance and make a choice. Hence, if, in the eyes of the voter, the incumbent party or candidate was not able to handle the economy in a satisfactory manner it would negatively influence his or her voting consideration with regard to that party. Tufte (1975) as well as Fair (1978) have also presented evidence for this theory, stressing that the individual voter considers economic circumstance in his or her immediate past when making an electoral choice. Most support was hence found for observations of economic factors one year prior to the election, which can readily be considered when analysing the factors that influence voting behaviour.

\section{Theory of the Performance Evaluating Voter}

Furthermore, Fair (1978) outlined three general theories of voting behaviour. In the first theory Stigler (1973) expects that a well-informed voter evaluates the parties' performance and forms expectations about his or her future utility under each party in order to make a utility maximizing electoral choice. This theory is consistent with standard economic theory as it displays the voter as a rational being that can obtain all the information needed to make a choice and more importantly, knows which factors are important for his evaluation. The second theory by Kramer (1971) assumes that information about the parties' performance is not easily obtained and costly. Consequently, the individual acquires only little 
and easily observable information and votes for the incumbent party (or candidate) if its performance has been satisfactory. Lastly, Downs displays the voter as a self-interested being that acquires some information about the parties while the exact amount of information remains unclear in this situation. Fair (1978) therefore assumes that Downs theory closely resembles the first theory. The apparent discrepancy between the theories with regard to the rationality of the voter sure is an interesting topic to look into but will not be examined in more detail in this study. Regardless of which researcher's theory is to be given more credibility, both agree on the fact that the individual voter attempts to evaluate the incumbent's performance before coming to an electoral choice. Hence, the study incorporates the incumbent's performance over the last legislative period with respect to the factors analysed.

The question much of the research on voting behaviour circles around is what dimensions the voter considers for such evaluation. So far, existing literature has made a strong case for economic conditions being an important factor when it comes to voting behaviour. This study therefore leans on this literature and focused on economic factors when analysing the 2016 U.S. presidential election. Supported by prevailing theories as well as reasonable assumptions and expectations, the following economic dimensions are being considered in this study.

\subsection{Economic and Non-Economic Factors}

\section{Income}

As Tufte (1980) suggests, real disposable income and fluctuations thereof are a good signal for stimulation of the economy prior to elections. The time lag between short-term government actions and changes in real disposable income is fairly small and effects are direct and immediate. The relevance of changes in real disposable income for electoral choice has thus been tested and determined by several studies, such as Markus (1988), Fair (1978) and Kramer (1971). Stigler (1973) also outlines the importance of income for electoral choice and concludes that income policies should be the most important factor for individuals to side with a party.

\section{Unemployment}

In his book on the American political economy Hibbs (1989) notes that unemployment is commonly seen as a significant indicator for the health of the economy and fluctuations in it are closely related to real income. He also points out the indicator's relevance to the individual voter, saying that "it is generally taken to be a useful index of individual hardship" (Hibbs, 1989, p. 42). Although the results of Fair (1978) and Kramer (1971) oppose each other with regard to this factor, the argument by Hibbs gives reasonable support for the hypothesis that unemployment impacts a voters decision.

\section{Globalization}

Globalization, and especially profitable globalization includes that firms from industrialized economies seek cheaper labour force in yet developing countries and outsource their activities, which causes job loss in their countries of origin (Hendee, 2010). As such job loss is a real economic circumstance individuals in the U.S. have to deal with, it is important to include a measure for this dimension into the analysis. Levine (2012) notes that offshoring in the manufacturing sector has been going on for years and accounts for a considerable fraction of U.S. job loss. The US Bureau of Labor Statistics (BLS) summarized that employment in the manufacturing sector had been falling in the period of 2004 to

\footnotetext{
18 Research Papers
} 
2014, whereas it grew in the services sector. Prognoses for the period of 2014 to 2024 are consistent with this trend, with the manufacturing sector experiencing falling and the services sector experiencing growing employment (Henderson, 2015). This observable trend and consequent threat of job loss suggests that employment in the manufacturing industry could be a factor voters consider when making their choice.

\section{Income Inequality}

Galbraith and Hale (2008) tested for the relationship between inequality, spatial-economic segregation, voter turnout and electoral choice in U.S. presidential elections with fixed effects, cross-section and multilevel analyses. They argue that higher income inequality decreases the income of the lower class, which might result in a higher political participation and interest. The results of the study suggest that while a higher income inequality on the state level leads to a lower voter turnout, it increases the preference for the Democratic Party.

In order to account for as much variation in the electoral outcome as possible, the following noneconomic factors will be added to the analysis as well.

\section{Education}

In his work on political participation, Galston (2004) claims that civic knowledge, which is obtained through education, increases participation in political processes. It supports individuals in identifying their interests and protecting those through political participation (Galston, 2004). In their study Achterberg and Houtman (2006) attempt to explain 'unnatural' voting behaviour which they define as not following the traditional voting pattern of one's social class. They find that voting behaviour and especially voting unnaturally can, amongst others, be explained by educational attainment. Expecting that voting against one's classes' traditional voting pattern requires an even more considered and informed decision making, educational attainment is seen as an important factor to be tested in this study.

\section{Illegal Immigration}

This factor will not concern immigrants in the U.S. but rather the probability of illegal immigration to the state an individual resides in. In the last decade illegal immigration has risen heavily in the U.S. and has thus not only become an immediate political topic but also subject to public debate. Driven by the media's presentation of illegal immigration, the picture drawn in the U.S. often links illegal immigrants to crime, smuggling, drugs and trespassing (Kim, Carvalho, Davis, \& Mullins, 2011). Those depictions as analysed by Kim et al. (2011) in their study of how the media frames illegal immigration supports the assumption that immigration could be a factor voters consider in their electoral choice. By far the greatest share of illegal immigrants is of Latin American origin (Kim et al., 2011), which is why this study will particularly include the immediate probability of illegal immigration from Latin American countries to the state a voter is registered in.

\section{Age and Gender}

Based on the statistics derived from an Edison Research survey conducted across 25,000 voters, it was claimed that younger people tended to vote against Donald Trump (BBC, 2016). Additionally, it seems reasonable to assume that people from different age categories have different interests which influence their electoral choice. With respect to gender, the Edison Research statistics suggest that females were 
more likely to vote for Hillary Clinton. Consequently, this study includes those two demographic factors in the model.

\section{Race and Ethnicity}

In their work on the relation between race or ethnicity and political participation, Leighley and Vedlitz (1999) outline that previous studies have often claimed that race or ethnicity can, even when controlling for socioeconomic status, significantly influence vote participation. Although the authors did provide some conflicting evidence on those previous models, race and ethnicity is still an interesting factor to look at with regard to the analysis.

\section{Religion}

Green (2007) provides substantial evidence for the phenomenon of coalition building among religious groups and presidential candidates in the U.S. presidential elections, using the example of the 2004 presidential election. Minkenberg (2010) analyses confessional voting and finds that although pure confessional voting is declining, church religiosity (that is church going) still has a considerable impact on voting behaviour. As those two studies point out, it is reasonable to expect a relation between one's religion and voting behaviour, which will thus be tested in this study.

\subsection{The Research Approach}

This study attempts to analyse the outcome of the 2016 presidential elections by building upon and using the framework of existing research as presented in the preceding sections. Studies like the work of Kramer (1971) and Fair (1978) form the support for the main research interest of testing for the importance of economic factors for the electoral outcome at hand. Additionally, Markus (1988) and Fiorina (1978) provide evidence that the interest in personal economic circumstances as opposed to national economic conditions is a reasonable way to look at voter behaviour. The primary interest of this study lies with the individual voter and his or her economic situation. However, data for each of the above mentioned dimensions is not practically obtainable for each individual voter or a representative sample of voters. Consequently, the focus has to be extended in order to bring the analysis to a level where the research question can be analysed reliably. The most reasonable approach to this is to concentrate on county level data. This work assumes that variations in the variables under analysis are sufficient to provide a pattern of behaviour on this level, from which individual (or group) behaviour can then be inferred. Although this study focuses on the 2016 presidential election in particular, it generally attempts to create a model of voting behaviour that is generally applicable. As the analysis conducted combines established theories in one model, focusing not only on economic but on economic and noneconomic factors together, and applies it to the most recent presidential election, it is expected to valuably add to the existing literature.

The theoretical framework underlying the research interest as well as the proposed model outlined in the next section has motivated hypotheses about the outcome of the analysis. It is expected that especially economic but also non-economic factors considered in the analysis significantly impacted the electoral outcome of the 2016 U.S. presidential election. Considering the retrospective voter theory economic circumstances one year prior to the elections are expected to particularly influence voting behaviour. Moreover, the theory of the performance evaluating voter considered in the analysis supposes that changes in economic factors during the last legislative period are an important determinant of electoral

\section{Research Papers}


choice. Therefore, it is expected that people whose economic position has worsened in the years before the election gave more support to the non-incumbent party candidate Donald Trump.

\section{Methodology}

To answer the research question in this study, a quantitative analysis was conducted. The empirical approach taken was a multiple regression using ordinary least squares for its estimation, in order to test for several variables simultaneously.

Data on all variables of interest was obtained from a collection of freely accessible databases of the United States Government or other institutions. The variables were collected at the county level and the analysis generally considered data from the year 2015, one year prior to the election, in order to take into account the retrospective voter theory as outlined above. Where necessary, the data was further transformed before the analysis. In general, for all economic factors in the analysis the change in the variable from 2012 to 2016 (or the latest value available) was calculated in order to be able to infer the performance evaluating behaviour of voters by considering the Democratic Party's performance in the last legislative period. Table 3 in Appendix A gives an overview of all variables used for the analysis.

The dependent variable of the analysis is the Relative Votes for Donald Trump. The 2016 election results on the county level were obtained from a dataset that was compiled and made available by McGovern (2016). For the computation of the variable the total votes for Donald Trump were retrieved from the dataset and divided by the total voting population. Data on the total voting population, that is, all legal citizens over the age of 18, was obtained from the 2011-2015 American Community Survey's ${ }^{2}$ five year estimate (United States Census Bureau, 2015b).

The variable Income 2015 is the per capita disposable personal income, which is calculated by dividing total disposable personal income by the total midyear population of a county, and was retrieved from the Bureau of Economic Analysis (2012, 2015a). The same dataset was used to calculate the variables Income ${ }^{2}$ and Income Change 2012-15. Unemployment 2015 and Unemployment Change 2012-16 are based on the unemployment rates (as a percentage of the labour force) by county obtained from the Bureau of Labor Statistics $(2012,2015,2016)$. The globalization variable described previously is quantified in this analysis by the percentage of employment in manufacturing. Hence, to calculate the variables Manufacturing Employment 2015 and Manufacturing Employment Change 2012-15, the employment in manufacturing was divided by the total employment. The relevant data was retrieved from the Bureau of Economic Analysis (2012, 2015b). For the variables Income Inequality 2015 and Income Inequality Change 2012-15 the values of the Gini coefficient were obtained from the United States Census Bureau (2012, 2015). With respect to education the American Community Survey provides a detailed dataset for five year estimates of educational attainment (United States Census Bureau, 2015c). Based on this dataset the variables No College Degree and Bachelor's Degree were calculated as the percentage of the population that attended some college but has no degree or an associate's degree (lower education category) and the percentage of the population that has a bachelor's

\footnotetext{
2 The American Community Survey (by the US Census Bureau) is a monthly survey that creates annual estimates and comprises data on 2,3 million households in the US, which covers 92,8 percent of the total population.
} 
degree or higher (higher education category), respectively. The variable Illegal Immigration is represented by a dummy, taking on the value of one if the state in which the county lies borders Mexico. Gender is represented by the relative percentage of Female population in a county. Data on gender and age were obtained from the American Community Survey's five year demographic and housing estimates $^{3}$. Based on the same dataset three categories were created, Age 20-34, Age 35-64 and Age $65+$, and calculated as a percentage of the total county population (United States Census Bureau, 2015b). Data on race and ethnicity was retrieved from a dataset of the five year estimates of the American Community Survey (United States Census Bureau, 2015a). Based on this dataset the variables Race BLACK, Race WHITE and Race HISPANIC were calculated, representing the respective race as a percentage of the total population. With respect to religion, data on adherents to a certain religion was obtained for the year 2010 from the U.S Religion Census via the Association of Religion Data Archives (2010). For the analysis three categories, Religion EVANGELIC, Religion MUSLIM and Religion CATHOLIC, were computed as a percentage of the total county population in 2010.

The analysis considered all data at the county level, which are administrative and political subdivisions of states. In total there are 3142 counties in the U.S. All counties in Alaska and 17 other counties were excluded before the analysis due to missing or incompatible data on the votes for Donald Trump, which resulted in 3095 usable observations.

\section{Analysis}

The multiple regression analysis was performed for the dependent variable of relative votes for Donald Trump and the independent variables described above. For the purpose of analysing the proposed model in detail, the regression was conducted for different forms of the model. In order to test for assumptions, normal probability plots of residuals and scatter diagrams of residuals versus predicted residuals were examined for all models. No violations of normality, linearity or homoscedasticity of residuals were encountered. Table 1 and Table 2 below show the regression statistics for all analyses performed.

Model 1 is the basic model that only includes economic variables. The analysis of Model 1 involved 2635 valid observation and nine independent variables. The model significantly predicts relative votes for Donald Trump with an F-statistic of 51.316 . The $\mathrm{R}^{2}$ of the model indicates that it accounts for about $15 \%$ of variability in the relative votes. At the $5 \%$ significance level, four variables significantly predict the dependent variable. The results show that the Income Change 2012-15; the Unemployment 2015 and the Income Inequality 2015 variable negatively impact the relative votes. An increase in Income Inequality Change 2012-15 on the contrary is associated positively with the votes for Trump. The standardized regression coefficients of the variables are based on changes in standard deviation units and thus make different variables and their respective effect comparable. Looking at the standardized coefficients in Model 1, Income Inequality 2015 seems to exhibit by far the strongest impact of all economic variables, followed by Unemployment 2015.

\footnotetext{
${ }^{3}$ Demographic data from the American Community Survey are estimates from 2015 and are assumed to reliably represent the population characteristics at the time of the election in 2016.
}

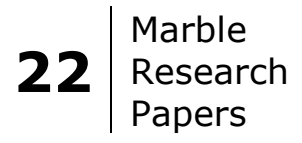


Model 2 extends Model 1 by a number of non-economic variables and represents the actual model of interest in this study. It includes 2635 observations and 16 independent variables. The model shows to have significant predictive power with an F-Statistic of 169.015. The $\mathrm{R}^{2}$ of the model implies that Model 2 accounts for about $56 \%$ of the variation in the relative votes. In total twelve variables significantly predict relative votes for Donald Trump. Unemployment 2015; Manufacturing Employment 2015; Income Inequality 2015; Bachelor's Degree; Female; Religion MUSLIM and Age 20-34 negatively and statistically significantly impact the relative votes for Trump. The variables No College Degree, Religion EVANGELIC and Race WHITE positively influence the results for Trump. With respect to income, the analysis of Model 2 also shows that Income 2015 and Income $2015^{2}$ are statistically significant. The variable Income 2015 is predicted to positively impact the relative votes, while the negative coefficient of the Income $2015^{2}$ variable suggests a concave relationship between income and the dependent variable. The standardized coefficients suggest that Income 2015 has the strongest impact of all economic variables, while Race WHITE and Age 20-34 seem to be the most important non-economic variables.

Model $2 \mathrm{a}, 2 \mathrm{~b}, 2 \mathrm{c}$ and $2 \mathrm{~d}$ are variations of Model 2 . The variations alter the age and race variable (which each contains three different categories) as including all categories at once could lead to high correlation among the categories or might result in the variables cancelling each other's effect. Hence, Models $2 a$ and $2 \mathrm{~b}$ vary in the age category and Models $2 \mathrm{c}$ and $2 \mathrm{~d}$ alter the race variable. All variations of Model 2 significantly predict the relative votes for Donald Trump. In contrast to the observations about the youngest age category, the analysis shows that Age 35-64 in Model 2a and Age 65+ in Model 2b both exhibit a significantly positive impact on the votes for Donald Trump. However, the coefficients suggest that the effect of the two older age categories is far weaker than the impact of Age 20-34. Models 2c and $2 \mathrm{~d}$ predict a negative effect of Race BLACK and Race HISPANIC on relative votes.

Overall some variation can be observed in the variables across the two different models as well as across the different versions of Model 2. Hence, several conclusions can be drawn from the analysis of all models. Income 2015 exhibits a significantly positive impact among all models, whereas the significant coefficient of the Income $2015^{2}$ term suggests a concave relationship between income and relative votes. The Income Change 2012-15 variable is only significant in two of the models. However, in cases where the variable is predicted to have a significant effect, it is negatively related to the dependent variable. Unemployment 2015 is also constantly significant in all models and predicts a negative relationship with relative votes. Unemployment Change 2012-15 on the contrary is not significant in any of the models.

Manufacturing Employment 2015 is significant in all versions of Model 2 and is predicted to have a negative impact on the dependent variable. In contrast, Manufacturing Employment Change 2012-15 shows a significantly positive impact in only one model. The variable Income Inequality 2015 has a significantly negative effect on the relative votes in all models. Income Inequality Change 2012-15 exhibits a positive relationship in two models. No College Degree is predicted to have a significantly positive impact in some versions of Model 2, whereas Bachelor's Degree shows a significantly negative effect in all models. Illegal Immigration does not exhibit a significant effect in any of the models. The variable Female is significant in three models and predicts a negative relationship. Religion EVANGELIC and Religion MUSLIM are significant across all models and show a strongly positive and strongly negative 


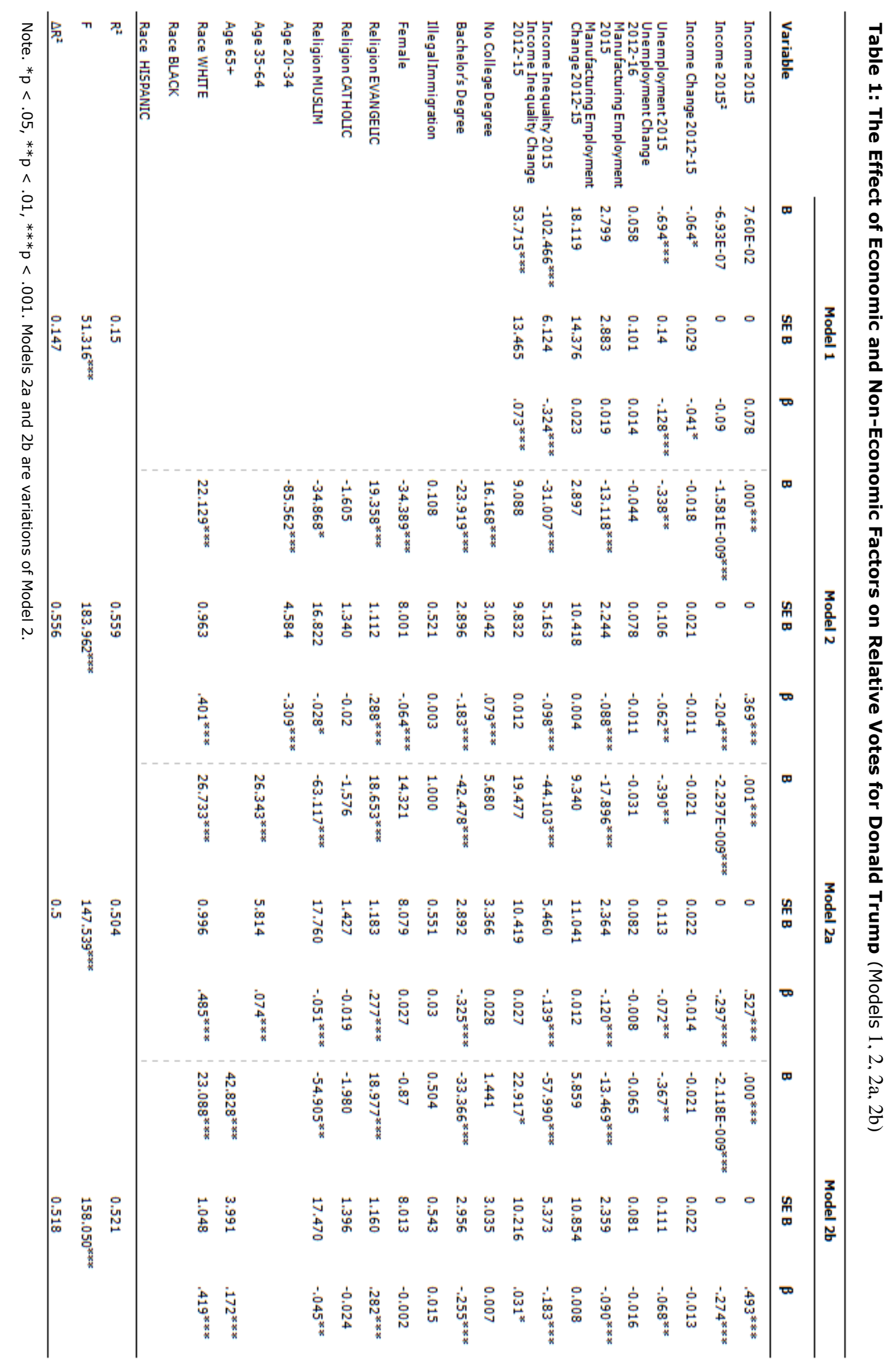

$24 \begin{aligned} & \text { Marble } \\ & \text { Research } \\ & \text { Papers }\end{aligned}$ 


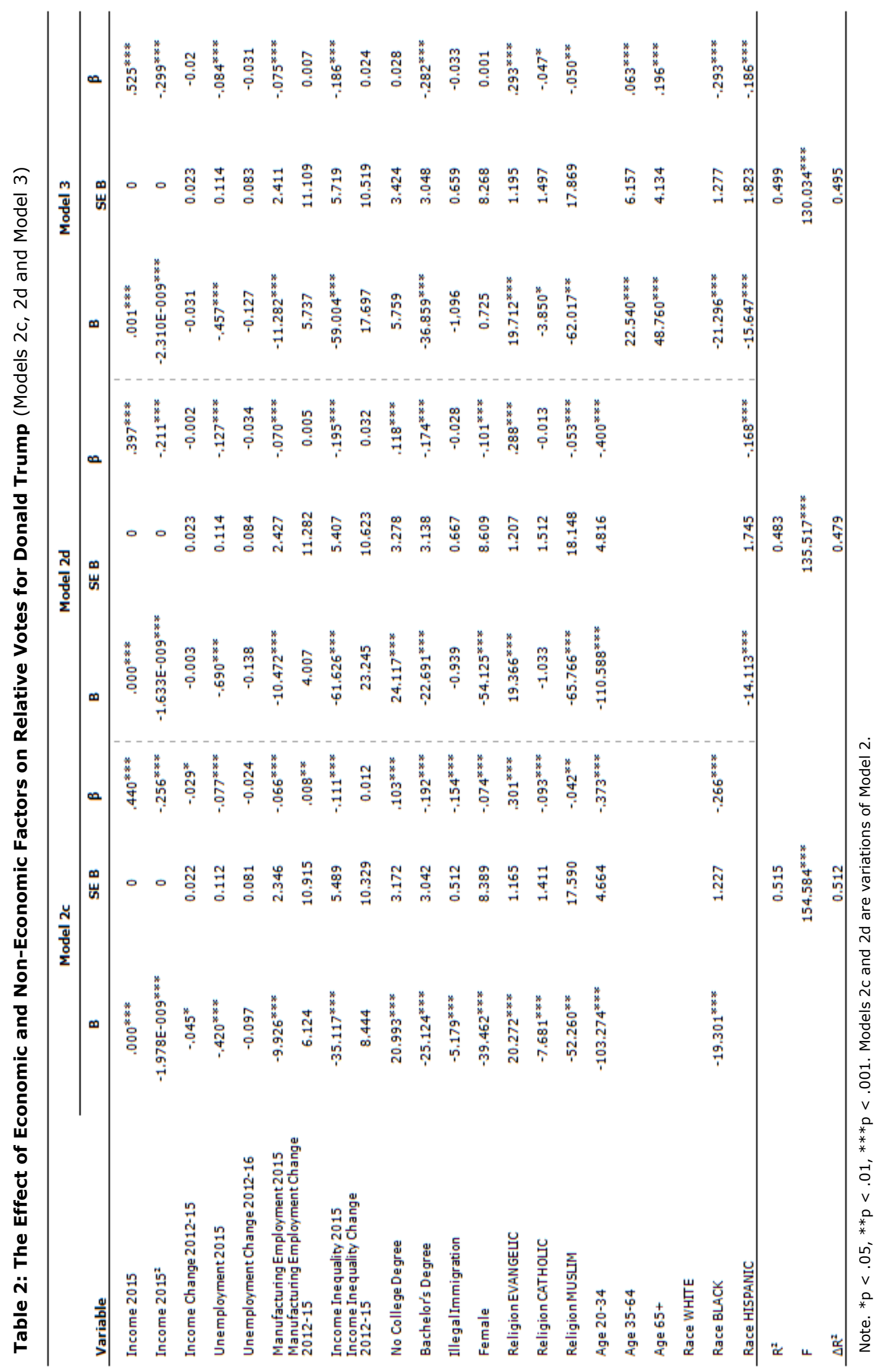


effect respectively. Religion Catholic exhibits a significantly negative effect in only two versions of Model 2 and is otherwise insignificant.

After including different age and race categories stepwise in the above described models, it makes sense to wonder what results a model with more than one category of the two variables would give. The three age categories as well as the three races considered already cover almost all of the voting population. Thus, including all categories of the two variables in one model bears the risk of the variables cancelling each other's effect. Therefore, Model 3 includes two age and two race categories to, additionally to the general analysis of the variables, test a model that contains more than one age and race category. The results of Model 3 suggest that Unemployment 2015, Manufacturing Employment 2015, Income Inequality 2015, Bachelor's Degree, Religion CATHOLIC, Religion MUSLIM, RACE BLACK and RACE Hispanic have a significantly negative effect on relative votes for Donald Trump. Religion EVANGELIC, AGE 35-64 and Age 65+ on the other hand predict a positive effect. Income exhibits the same inverted u-shaped relationship as in Model 2. Therefore, Model 3 displays fairly similar results as Model 2 and shows the same direction of the relationship for the two age and two race categories included as under the separate analyses. With regard to the magnitude of the effects, the model predicts a similar pattern as previous models with Income 2015 and Income Inequality 2015 exhibiting the strongest effect among the economic variables. Bachelor's Degree, Religion EVANGELIC and Race BLACK seem to be the most important non-economic factors.

Comparing the magnitude of the impact of the variables on relative votes, and hence the importance of each respective variable, the results of the analysis suggest certain conclusions. Considering only economic variables, Model 2 (and all its versions) shows that the Income 2015 and Income $2015^{2}$ variables exhibit the strongest impact on the votes for Trump, exceeding the effect of Income Inequality 2015, which was found to have the highest standardized coefficient in Model 1. Nonetheless, Income Inequality 2015 still has a comparably strong impact in the variations of Model 2 . With respect to the non-economic factors in the analysis, Race WHITE and Age 20-34 show the strongest impact. Overall, the magnitude of economic and non-economic variables seems to be comparable across the models, especially for those variables that are significant in all versions of Model 2. Most importantly, the standardized coefficients clearly support the importance of economic factors and their impact on relative votes for Trump.

As an addition to the main analysis presented, the proposed model was further applied to the 2012 presidential election in order to test the generalizability of the model and its results. This out of sample robustness test (see Appendix B) confirmed expectations drawn based on the results of the main analysis, but overall demonstrate that the proposed model is only partly applicable to the 2012 election.

\section{Discussion}

The question examined in this study is: How important are economic factors when it comes to voting behaviour? More specifically, the research question was studied with regard to the 2016 presidential elections in the US. Besides analysing which factors determined the outcome of the 2016 U.S. presidential election, the analysis was to test two prevailing theories of voting behaviour, the

$26 \mid$\begin{tabular}{l|l} 
Marble \\
Research \\
Papers
\end{tabular}


retrospective voter theory and the theory of the performance-evaluating voter. It was therefore expected that several economic factors as well as the change in such factors over the last legislative period were influential to the electoral outcome. In addition, it was presumed that several non-economic factors would add valuably to the model with respect to its predictive ability. In light of the hypotheses made as well as the relevant literature examined, the findings of the empirical analysis conducted will be discussed critically. Overall, two main findings can be summarized.

\subsection{First Finding: Economic Factors}

The first finding is that all four economic factors included in the analysis were shown to significantly predict the electoral outcome. All static variables that measure the current state of the economy in 2015 were significant across all versions of Model 2, giving considerable support to the retrospective voter theory as outlined by Fiorina (1978) and supported by Fair (1978) and Tufte (1975). However, the variables measuring the change in economic circumstances vary in their significance across the models, which gives only limited support to the theory of the performance evaluating voter as advocated by Kramer (1971). With regard to the economic variables analysed, the most important findings can be summarized as follows. The unemployment rate that was considered in the analysis reveals that a higher unemployment rate (one year prior to the election) negatively influences the support given to Donald Trump by the voters in a particular county. This finding suggests that people in a worse economic state were generally less likely to support Donald Trump. Although the unemployment rate seems to impact voters' choices, the change in the unemployment rate over the previous legislative period and hence the performance of the incumbent is not being considered by voters. As Fair (1978) found that changes in unemployment one year prior to the elections significantly influence voting behaviour, the results of this study do in part contradict his conclusions, supporting the significance of unemployment but not the importance of changes in unemployment. The relative manufacturing employment in a county was included in order to approximate the importance of the manufacturing industry ${ }^{4}$ in the area, with the expectation that a higher percentage employment in manufacturing would influence the votes in favour of Donald Trump, who is greatly opposing globalization and the trend of outsourcing. However, this expectation was not supported by the model, which displays that the higher the manufacturing employment, the lower is the support voters give to Donald Trump. Although this does not mirror the intuitive reasoning behind the variables, it could be related to the initial expectations in the sense that as long as the employment in manufacturing is still high in a state, the population does not feel any threat of outsourcing and hence does not feel the need to support Trump. Further, it could be argued that manufacturing workers have a lower socioeconomic status compared to other industries. This would imply that voters with a lower socio economic status are less supportive of Donald Trump, which is in line with the above findings about the effect of unemployment on voting behaviour. However, the latter interpretation has to be viewed with caution as there are more factors determining an individual's socioeconomic status.

The most conclusive findings in this study are with regard to income and income inequality, which have shown to significantly affect voting behaviour, exercising the strongest impact of all economic variables

\footnotetext{
${ }^{4}$ As mentioned above, a high reliance on the manufacturing industry could present a greater perceived threat from globalization and outsourcing.
} 
analysed. The personal income was shown to be an important factor for the electoral outcome, exercising a positive effect on the votes for the non-incumbent party candidate Donald Trump. Nonetheless, the analysis has indicated that a non-linear relation persists, which suggests that beyond a certain level, a higher income negatively affects the votes. Further, the results demonstrate that a positive change in personal income during the previous legislative period negatively influences the support for Trump and hence affects the votes in favour of the incumbent party, which is in line with the theory of the performance evaluating voter. As income has previously been shown to significantly influence voter behaviour and electoral outcomes (cf. Fair (1978); Kramer (1971) and Stigler (1973)), the findings of this study are in line with previous studies. As income is measured as personal income per capita the observation of the positive impact of income on votes for Donald Trump can be interpreted in two ways. First, the most straightforward interpretation would be that people with a higher income were more likely to support Trump. Second, a high per capita income could also be the result of a county habiting a few rich and many poor people, which would lead to the opposing interpretation that poorer people were more likely to support Trump. The analysis further showed that higher income inequality in a county leads to less votes for Trump. Again this finding is relatable to the above findings, indicating that people in a weaker economic position were less likely to vote for Donald Trump in the 2016 presidential elections. Additionally, this result confirms the conclusions of Galbraith and Hale (2008) who found that increased income inequality leads to more support for the Democratic Party. This effect of income inequality on a voter's choice might give some clarity about the interpretation of the findings on income. As it shows that people living in a county with high income inequality are less likely to vote for Trump, it supports the first interpretation that people with a higher income were more supportive of the Republican Party candidate. However, an increase in the Gini index in the period of 2012 to 2015 is predicted to have a positive impact on the votes, which is in line with the expectations formed based on the theory of the performance evaluating voter, as it predicts a 'punishment' for poor performance of the incumbent party and its candidate.

\subsection{Second Finding: Non-Economic Factors}

The second finding is that several non-economic factors added to the model have shown significant predictive power with respect to the electoral outcome. With regard to education, it can be said that the analysis has demonstrated that a higher education of voters results in less support for Donald Trump. Although gender was, due to its approximately equal distribution across the counties, not expected to exert a significant effect, several of the models examined predict that female voters are less likely to support Donald Trump. Such finding can be interpreted as being either due to his political and personal position or due to the opposing candidate, Hillary Clinton, appealing more to women with her politics. The voters' age was also proven to be an important factor determining voting behaviour. The youngest age category included in the analysis represents most of the millennial generation. The findings from the analysis are that the millennial generation is less likely to vote for Trump while the results for the other two age categories suggest that older people gave more support to Trump. This trend in age is highly interesting and at the same time raises the question of what causes this trend. Is it that the millennial generation specifically has a different political opinion or can differences between age groups be explained by different economic interests and demands in general? The different races and ethnicities involved in the analysis have shown that a higher percentage of black or Hispanic population exerts a negative impact on the votes for Donald Trump while a higher fraction of white population shows the

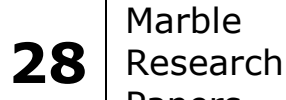
Papers
} 
opposite effect. However, the effect captured by these findings can be twofold. On the one hand, it could mean that black or Hispanic people are less likely to vote for Trump (which might reasonably be assumed). On the other hand, it could reflect that in an area with a larger fraction of blacks or Hispanics the overall voting population (including other races and ethnicities) is less likely to support Donald Trump. A similar issue applies to the results for a different religion and age group. The dummy that was included to capture the impact of illegal immigration on the electoral outcome was expected to have a positive effect on the votes for the Republican Party candidate, which would mean that people that live in a state that borders Mexico would be more likely to vote for Donald Trump. The variable did not show any significant effect. However, this finding does not mean that illegal immigration was no considered by voters in the 2016 election or is not taken into account by voters in general. Merely it reflects that the measure chosen to represent the impact of illegal immigration on electoral choice does not predict an effect, which could be different under another measure. With regard to religion, it can be concluded from the results that Muslims are less likely to vote for Donald Trump which is an intuitive finding. Considering the Christian population, Evangelism positively impacts the electoral outcome for Trump whereas Catholicism is not significant in most models. It might be argued that generally the Christian population could be expected to show more support for Donald Trump, as he is strongly opposing abortion which goes with the strictly Christian belief. However, only Protestants seem to show such effect while Catholics are predicted to have a negative effect in the two models in which the variables is significant.

\subsection{Limitations and Future Research}

The results and conclusions of this study rely on data collected from databases on the county level, which were used to infer about individual behaviour. This method can be seen as a limitation of this study and its findings as it poses a considerable challenge on the representativeness of the data and the model. Individual voter characteristics on the variables of interest would greatly increase the external validity of the results and would provide an improved basis for the formation of a theory on voting behaviour. Additionally, it would solve the twofold interpretation of the results for races, age and religious groups discussed earlier. Future research should concentrate on compiling a large enough individual level dataset on voter characteristics and their electoral choice in order to not only infer individuals' voting behaviour but actually observe it directly. Moreover, the research question was analysed with regard to one particular election, which could limit the external validity of the results as many of the relations observed could be due to characteristics specific to the 2016 U.S. presidential election and its candidates. ${ }^{5}$ Another direction in which additional research could go is to concentrate more on what variables can actually be observed by the voter i.e. how an individual observes and measures for instance income when making an electoral choice. Analysing and assessing the rationality of voters could also greatly add to the understanding of voter behaviour. Moreover, including national as well as individual economic circumstances could valuable add to this study and extend its focus. In terms of the model presented in this paper the factors at hand could be not only included at the county (individual) level but also as national statistics. Another limitation and at the same time opportunity of the model is its selection of economic and non-economic factors. Further research could always add

\footnotetext{
${ }^{5}$ An out of sample robustness test conducted with respect to the 2012 election (see Appendix B) however supports the main findings of the analysis, although the model's fit decreases with this application.
} 
more economic and non-economic variables to the model in order to increase its predictive ability or shift the focus of the analysis. To that regard, variables like the past loyalties of a voter or the public perception of the candidates and the impact of social media could create an interesting research direction.

\subsection{Implications}

The findings of this study hold different implications about the 2016 presidential election itself as well as about voting behaviour and electoral outcomes in general. The model in this paper was used to analyse which factors influenced the electoral outcome in the 2016 U.S. presidential election in particular. Although applying the model to other elections would show with more certainty how general the findings of this study are, some conclusions about voting behaviour in general can however be cautiously made. The political business cycle Nordhaus (1975) studied suggests that in democratic political systems a pattern of the incumbent's actions can be observed starting with austerity and ending with a rather unconsidered generous monetary policy. Related to the political business cycle theory, the findings of this study could thus be used by the incumbent party (or candidate) to motivate economic policies with a positive short term effect on economic variables the voter considers prior to the election in order to influence the voter in its favour. However, such practical policy implications and possible applications of the results of this study are rather speculative. Mainly this paper provides some interesting insight into the factors that lead to Donald Trump's victory in the 2016 U.S. presidential election. The results further reveal that other voter characteristics combined with economic circumstances influence a particular voting decision. In general the study and its respective findings extend the horizon of the research on voting behaviour, implying that a model combining economic as well as non-economic factors can give a more comprehensive theory of voting behaviour.

\section{Conclusion}

This paper attempted to answer the question of how important economic factors are for the electoral choice voters make. For that purpose the study analysed the 2016 U.S. presidential elections with regard to the factors that influenced Donald Trump's victory. The corresponding analysis has shown that economic factors have had an important impact on the votes for Donald Trump. Especially, income and income inequality were important economic variables that influenced voting behaviour. Additionally, the retrospective voter theory is strongly supported whereas the theory of the performance evaluating voter does not seem to hold. Hence, voters consider the economic conditions in the immediate past when making an electoral choice but tend to omit the performance of the incumbent in the last legislative period with regard to those economic conditions.

Moreover, it can be concluded that the combination of economic and non-economic factors as in the proposed model has significant predictive ability with regard to the 2016 U.S. presidential elections. Such combination should thus be further considered and extended by future research. In general the analysis of the model in this study gives considerable insight into the factors that influenced Trump's victory. To that regard it can be summarized that a higher per capita income as well as a lower income inequality lead to more support for Trump. Further, people with lower education, white people, males $30 \mid$\begin{tabular}{l|l} 
Marble \\
Research \\
Papers
\end{tabular} 
and older generations can be said to have been more likely to vote for Trump. However, it needs to be kept in mind that the results with respect to specific factors in this study are not always intuitive and their interpretation is sometimes ambiguous.

An application of the proposed model to the 2012 U.S. presidential election was analysed in order to test the generalizability of the model and its results. The results of this analysis showed that the model is only partly applicable to the 2012 election and therefore results need to be generalized with caution. However, the application supported the main analysis' finding that economic factors strongly impact election outcome.

Concluding it can thus be said that the analyses conducted showed that economic factors and especially income and income inequality are of considerable importance for voting behaviour in general. The proposed model has a strong predictive ability with respect to the 2016 U.S. presidential elections and therefore offers insight into the variables that influenced Donald Trump's victory. This study therefore adds valuably to the existing theories on voting behaviour, but also raises new questions and research directions so that electoral outcomes remain an interesting field of research.

\section{References}

Achterberg, P., \& Houtman, D. (2006). Why do so many people vote 'unnaturally'? A cultural explanation for voting behaviour. European Journal of Political Research, 45(1), 75-92. doi:10.1111/j.14756765.2005.00291.x

Analysis, B. o. E. (2012, 2015a). LOCAL AREA PERSONAL INCOME AND EMPLOYMENT, Personal Income, Population, Per Capita Personal Income (CA1). Retrieved 30.05.2017, from Bureau of Economic Analysis https://www.bea.gov/iTable/iTable.cfm?reqid=70\&step $=1 \&$ isuri $=1 \&$ acrdn $=7$ \# reqid $=70 \&$ step $=1$ \&isuri $=1$

Andrews, W., Katz, J., \& Patel, J. (2016, 08.11.2016). Latest Election Polls. Retrieved from https://www.nytimes.com/interactive/2016/us/elections/polls.html?_r=0

Association of Religion Data Archives (2010). 2010 U.S. Religion Census: Religious Congregations and Membership Study, 2010 (County File). Retrieved 20.06.2017, from Pennsylvania State University http://www.thearda.com/Archive/ChCounty.asp

BBC. (2016, 09.11.2016). Reality Check: Who voted for Donald Trump. Retrieved from http://www.bbc.com/news/election-us-2016-37922587

Bureau of Econoic Analysis (2012, 2015b). LOCAL AREA PERSONAL INCOME AND EMPLOYMENT, Total Full-Time and Part-Time Employment by Industry (CA25, CA25N) Retrieved 14.06.2017, from Bureau of Economic Analysis https://www.bea.gov/iTable/iTable.cfm?reqid=70\&step $=1 \&$ isuri $=1 \&$ acrdn $=7$ \# reqid $=70 \&$ step $=1$ \&isuri $=1 \&$ acrdn $=7$

Bureau of Labor Statistics (2012, 2015, 2016). Labour Force Data by County, Annual Averages. Retrieved 01.06.2017, from Bureau of Labour Statistics https://www.bls.gov/lau/\#tables

Fair, R. C. (1978). The Effect of Economic Events on Votes for President. The Review of Economics and Statistics, 60(2), 159-173. doi:10.2307/1924969 
Fiorina, M. P. (1978). Economic Retrospective Voting in American National Elections: A Micro-Analysis. American Journal of Political Science, 22(2), 426-443. doi:10.2307/2110623

Galbraith, J. K., \& Hale, J. T. (2008). State Income Inequality and Presidential Election Turnout and Outcomes*. Social Science Quarterly, 89(4), 887-901. doi:10.1111/j.1540-6237.2008.00589.x

Galston, W. A. (2004). Civic Education and Political Participation. PS: Political Science and Politics, $37(2), 263-266$.

Green, J. C. (2007). The Faith Factor: How Religion Influences American Elections: Praeger Publishers.

Hendee, J. G. (2010). Profitable Globalization and the Ethical Dilemma of US Job Loss. McNair Scholars Research Journal, 1(1), 7. Retrieved from: http://commons.emich.edu/mcnair/vol1/iss1/7

Henderson, R. (2015). Industry employment and output projections to 2024. Monthly Labor Review, U.S. Bureau of Labor Statistics. doi:https://doi.org/10.21916/mlr.2015.47

Hibbs, D. A. (1989). The American Political Economy: Harvard University Press.

Kim, S.-h., Carvalho, J. P., Davis, A. G., \& Mullins, A. M. (2011). The View of the Border: News Framing of the Definition, Causes, and Solutions to Illegal Immigration. Mass Communication and Society, 14(3), 292-314. doi:10.1080/15205431003743679

Kramer, G. H. (1971). Short-Term Fluctuations in U.S. Voting Behavior, 1896-1964. The American Political Science Review, 65(1), 131-143. doi:10.2307/1955049

Leighley, J. E., \& Vedlitz, A. (1999). Race, Ethnicity, and Political Participation: Competing Models and Contrasting Explanations. The Journal of Politics, 61(4), 1092-1114. doi:10.2307/2647555

Levine, L. (2012). Offshoring (or offshore outsourcing) and job loss among US workers. Washington, DC: Congressional Research Service.

Lewis-Beck, M. S., \& Stegmaier, M. (2000). Economic Determinants of Electoral Outcomes. Annual Review of Political Science, 3(1), 183-219. doi:10.1146/annurev.polisci.3.1.183

Markus, G. B. (1988). The Impact of Personal and National Economic Conditions on the Presidential Vote: A Pooled Cross-Sectional Analysis. American Journal of Political Science, 32(1), 137-154. doi: $10.2307 / 2111314$

McGovern, T. (2016). 2016 US County Level Presidential Results. Retrieved 27.05.2017 https://github.com/tonmcg/County_Level_Election_Results_12-16

Milanovic, B. (2016) Ökonom Milanović über Trumps Wahlsieg (The Economist Milanovic about Trump's Victory)/Interviewer: J. Gepp. Profil (magazine), Vienna, Austria.

Minkenberg, M. (2010). Party politics, religion and elections in Western democracies. Comparative European Politics, 8(4), 385-414. doi:10.1057/cep.2009.5

Nordhaus, W. D. (1975). The Political Business Cycle. The Review of Economic Studies, 42(2), 169-190. doi: $10.2307 / 2296528$

Rogers, S., \& Cage, F. (2012). Full US 2012 election county-level results to download. Retrieved from: https://www.theguardian.com/news/datablog/2012/nov/07/us-2012-election-county-resultsdownload

Stigler, G. J. (1973). General Economic Conditions and National Elections. The American Economic Review, 63(2), 160-167.

Tufte, E. R. (1975). Determinants of the Outcomes of Midterm Congressional Elections. The American Political Science Review, 69(3), 812-826. doi:10.2307/1958391

Tufte, E. R. (1980). Political Control of the Economy: Princeton University Press.

United States Census Bureau (2012, 2015). B19083 GINI INDEX OF INCOME INEQUALITY, 2011-2015 American Community Survey 5-year Estimate. from United States Census Bureau Marble

32 Research Papers 
https://factfinder.census.gov/faces/tableservices/jsf/pages/productview.xhtml?pid=ACS 15 5Y R B19083\&prodType $=$ table

United States Census Bureau (2015a). B03002 HISPANIC OR LATINO ORIGIN BY RACE, 2011-2015 American Community Survey 5-Year Estimates. Retrieved 13.06.2017, from United States Census

Bureau https://factfinder.census.gov/faces/tableservices/jsf/pages/productview.xhtml?pid=ACS $15 \quad 5 Y$ R B03002\&prodType $=$ table

United States Census Bureau (2015b). DP05 ACS DEMOGRAPHIC AND HOUSING ESTIMATES, 20112015 American Community Survey 5-Year Estimates. Retrieved 17.06.2017, from United States Census Bureau https://factfinder.census.gov/faces/tableservices/jsf/pages/productview.xhtml?pid=ACS 15 5Y R DP05\&prodType $=$ table

United States Census Bureau (2015c). S1501 EDUCATIONAL ATTAINMENT, 2011-2015 American Community Survey 5-year Estimates. Retrieved 01.06.2017, from United States Census Bureau https://factfinder.census.gov/faces/tableservices/jsf/pages/productview.xhtml?pid=ACS 15 5Y R S1501\&prodType $=$ table 


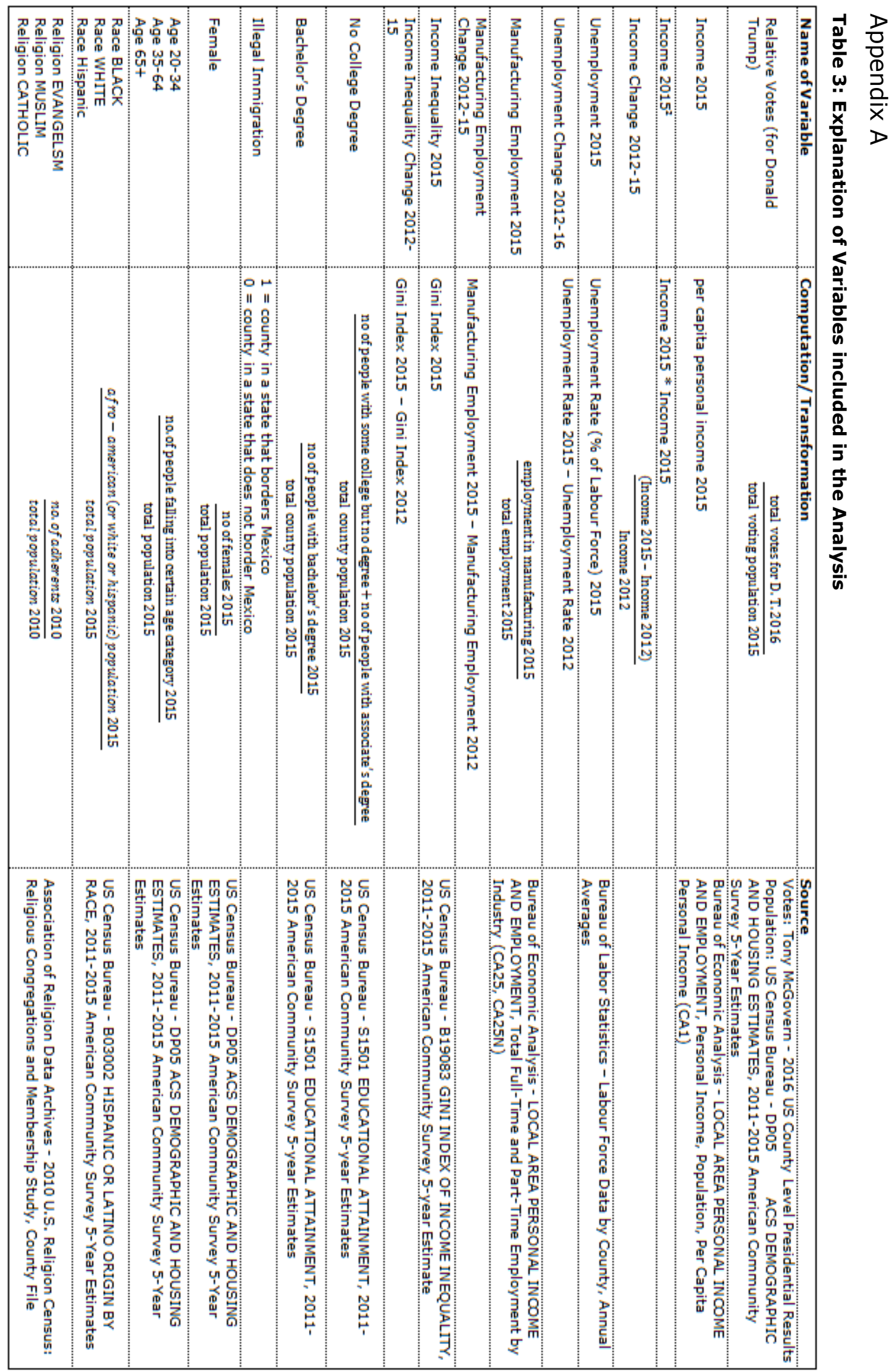

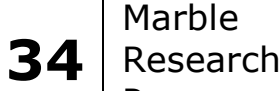




\section{Appendix B: Out of Sample Robustness Test}

Although the primary interest of this study is with individual voting behaviour in general, the method used in this study with its focus on the 2016 U.S. presidential elections might raise concern about the external validity of the results. Consequently, the proposed model was additionally applied to the 2012 U.S. presidential elections. The below briefly outlined analysis was thus conducted to test whether the results found and conclusions drawn from the above analysis are generally applicable to other elections or are merely specific to the 2016 election. This analysis is generally expected to give the opposite outcomes to the results from the main analysis on Trump as the 2012 winner of the election, Barack Obama, was a candidate for the Democratic Party and the incumbent candidate in the election (and therefore represented the opposite position to Trump).

The analysis is a replication of the main analysis of this paper in terms of method and data sources used. The variable Income Inequality Change was left out of this analysis due to lack of data. Data on the total votes for Barack Obama were retrieved from a dataset compiled by Rogers and Cage (2012), which resulted in 3104 usable observations.

The statistical results are displayed in Table 4 and Table 5 below. For the majority of the variables analysed the hypothesis stated earlier can be confirmed. Unemployment 2011, Manufacturing Employment 2011, Bachelor's Degree, Illegal Immigration, Female, Religion EVANGELIC, Religion CATHOLC, Race WHITE and Race BLACK all show the opposite impact as in the main analysis. Hence, the white population was less and the black population more likely to vote for Obama. Voters with higher education and females were also more supportive of Obama. Strikingly the results suggest the same inverted $u$-shaped relationship between income and the relative votes as before. Moreover, as before the variables measuring economic change in the last legislative period are not significant in most models. A less intuitive finding in this analysis is that the age variable displays a similar trend as in the analysis of the 2016 elections with the one difference that the effect of the youngest age category is inconclusive. The analysis finds that the most important economic factors for the 2012 election were Income 2011 and Unemployment 2011. With respect to the non-economic factors the Race BLACK and Race WHITE variables seemed to have had the strongest impact. In general it can be concluded that the fit of the models decreased considerably in this additional analysis, indicating that for the 2012 elections the model can only account for about $24 \%$ (as opposed to $56 \%$ before) of the variability in the votes for the winning candidate. Further, the results suggest that the magnitude of the economic factors is higher and the magnitude of the non-economic factors lower compared to the main analysis of the 2016 election.

The main conclusion from applying the model to the 2012 U.S. presidential election is that it only partly and less accurately explains another electoral outcome. However, the additional application also showed that the same factors were significant for the electoral choice and more importantly, supported the finding that economic factor do influence voting behaviour. Further, this analysis confirmed that circumstances one year prior to the election matter to voters whereas the change in those factors over the previous legislative period is much less important. 


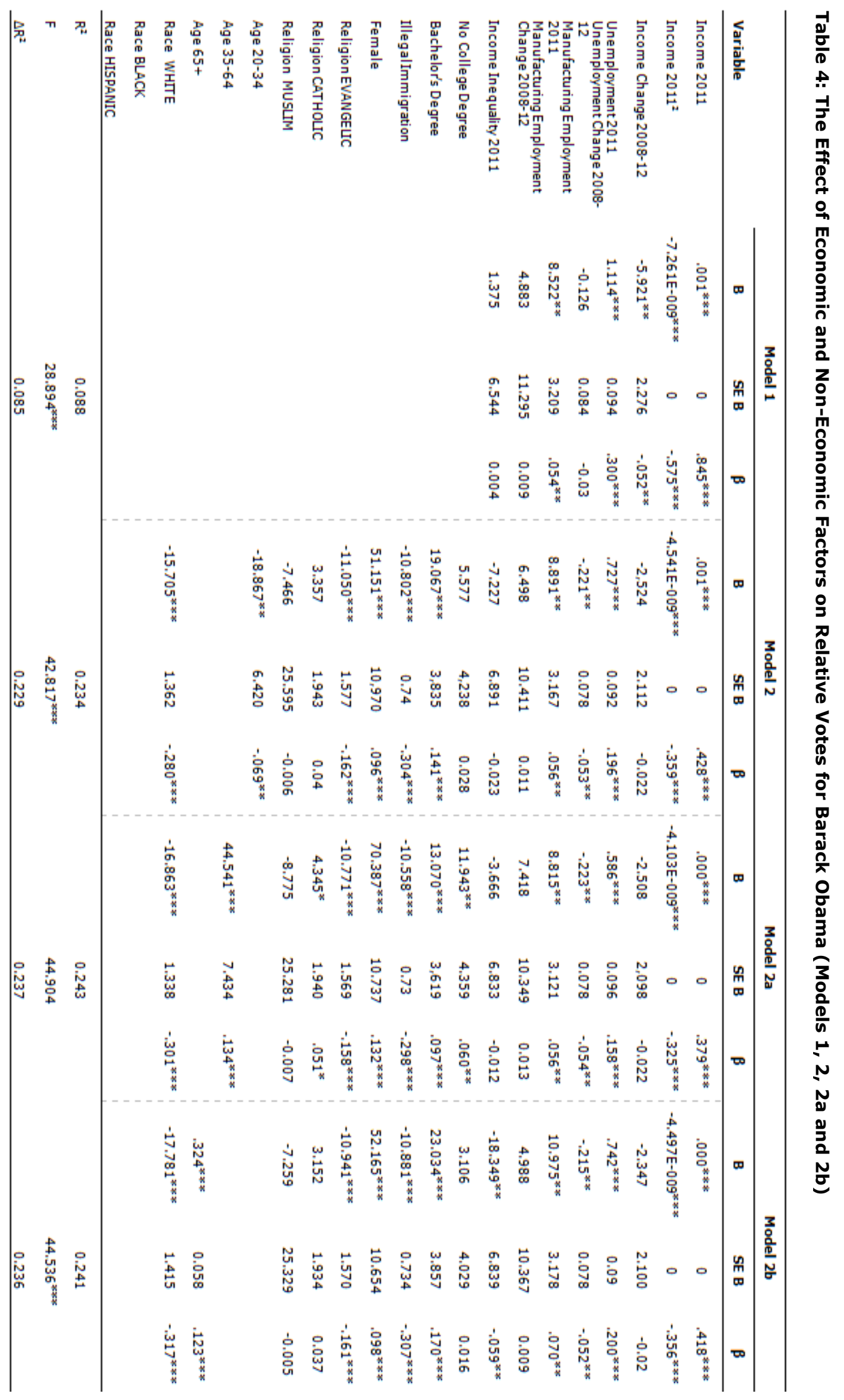

36 \begin{tabular}{l|l} 
Marble \\
Research \\
Papers
\end{tabular} 


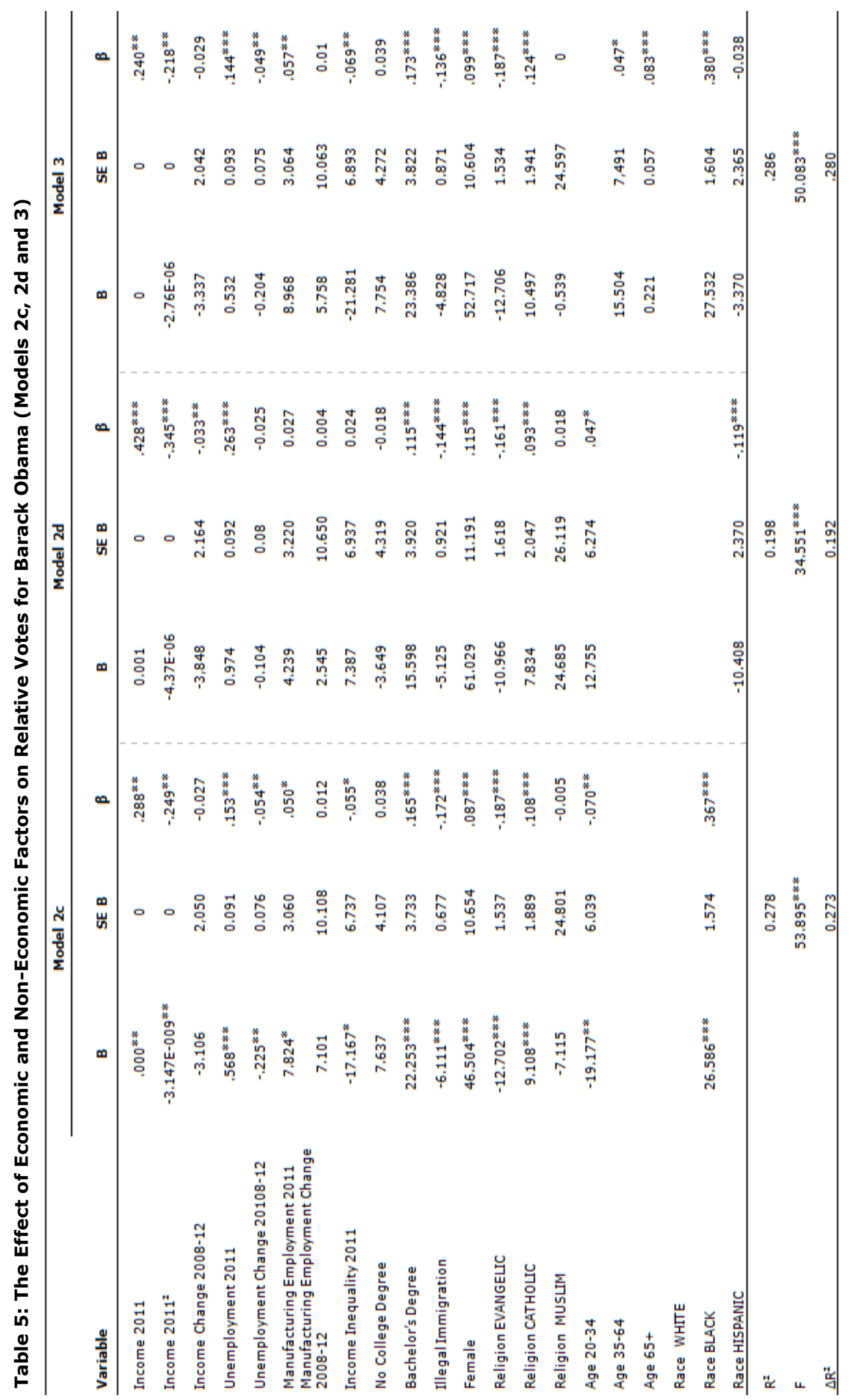

